\title{
Effects of Probiotics on Zebrafish Reproduction
}

\author{
Giorgia Gioacchini', Francesco Lombardo ${ }^{1}$, Daniel L. Merrifield ${ }^{2}$, Stefania Silvi ${ }^{3}$, Alberto Cresci ${ }^{3}$, Matteo Alessandro Avella ${ }^{1}$ and Oliana \\ Carnevali'*
}

${ }^{1}$ Dipartimento di Scienze del Mare, Università Politecnica delle Marche, Via Brecce Bianche, 60131 Ancona, Italy

${ }^{2}$ Aquaculture and Fish Nutrition Research Group, School of Biomedical and Biological Sciences, University of Plymouth, UK

3Università di Camerino, Scuola di Bioscienze e Biotecnologie, Via Gentile III da Varano, I-62032 Camerino (MC), Italy

\begin{abstract}
Recent studies have demonstrated that probiotics can influence reproductive performance, however, the mechanisms influencing oogenesis remain poorly explored. In this study, the effects of dietary probiotic Lactobacillus rhamnosus IMC 501 ${ }^{\circledR}$ administration was investigated on female zebrafish (D. rerio) reproductive performance and ovarian development (both growth and maturation phases). After feeding the zebrafish experimental diets for 10 days, real-time PCR and culture based methods revealed alterations on gut microbiota, characterised by high levels of $L$. rhamnosus IMC $501^{\circledR}$ in the gut of probiotic treated zebrafish, which were absent in the control. The microbial modulation in the gut was related with a significant increase of the gonadosomatic-index (GSI) associated, at the molecular level, to a significant increase of ovarian expression of cytochrome p 19 (cyp19a), hepatic vitellogenin (vtg) and the $\alpha$ isoform of the estradiol receptor (era) genes evidencing a positive role of probiotic administration on the ovarian growth phase. Concomitantly, a significant increase of signals which positively control the maturation phase such as, cyclin B, activin $\beta A 1$ and small mother against decapentaplegic 2 (smad2) genes in the ovary led us to confirm the beneficial role of the probiotic on maturation processes. Next to the enhancement of oocyte development processes by probiotic administration, an improvement of fecundity was evidenced which was associated with the increase of cyclooxygenase $2 a$ (cox2a) gene expression in the ovary. The significance of the results obtained herein underlines the importance of diet and gut microbes in the reproductive processes, supporting the hypothesis that feed additives could improve fecundity.
\end{abstract}

Keywords: L. rhamnosu; Danio rerio; Vitellogenin; Oocyte maturation Introduction

According to the World Health Organization [1] probiotic bacteria are defined as 'live microorganisms which when administered in adequate amounts confer a health benefit on the host'. Microbial products, such as probiotics, are considered valid alternatives to the prophylactic use of chemicals in aquaculture practices [2,3]. Recent studies have clearly demonstrated the beneficial effects of these feed additives on immune system modulation, stress tolerance and growth rate of farmed fish [4-7] but the effects of these nutraceuticals on reproduction and gamete quality, is still poorly studied $[8,9]$. In the above context, fish gamete quality is an important issue for the fish farming industry, especially for intensively cultured species; one of the most serious bottlenecks in the development of commercial aquaculture is the control of reproductive processes of fish in captivity since most of them exhibit reproductive dysfunctions. Reproductive problems are usually more serious in female broodstocks.

Over the past twenty years, the zebrafish (Danio rerio) has emerged as an excellent vertebrate model for studying genetics and development [10] and more recently, for the screening of therapeutic drugs [11-13]. Zebrafish have asynchronous ovaries, containing follicles of all five stages of development [14] and eggs are spawned throughout the year under laboratory conditions. The growth and the maturation of the oocyte occurs over a period of about 10 days $[15,16]$. Generally, in fish, ovarian development is divided into two major phases: growth and maturation. During the growth phase, vitellogenin, is produced in the liver under the control of estradiol $\left(\mathrm{E}_{2}\right)$. The production of estradiol in the zebrafish ovary follows similar synthesis pathways as other vertebrates. In the theca cells, cholesterol is converted into testosterone through a series of enzymatic conversions. Testosterone secreted from the theca cells diffuses into the granulosa cells and is finally converted to estradiol- $17 \beta$ finally converted to estradiol-17 $\beta$ by aromatase (P450Arom) encoded by cyp19a gene. Once released in to the blood stream vitellogenin is taken up by the developing oocyte and cleaved to yolk protein, which represents the nutritional reserve for the developing embryo [17-19]. Oocyte maturation in teleosts is stimulated by the release of luteinizing hormone $(\mathrm{LH})$ from the pituitary. The maturation phase is under the control of Maturation Inducing Hormone (MIH). MIH activates the cytoplasmic maturation promoting factor (MPF), which is made up of two subunits: cyclin B (a regulatory subunit) and cdc2 (a catalytic subunit). In zebrafish, MIH stimulates the de novo synthesis of cyclin B. Cyclin B proteins bind to cdc2 to form MPF. The newly formed MPF is activated by phosphorylation of cdc2 on threonine 161 . The active MPF, then, stimulates all the changes associated with oocyte maturation, such as germinal vesicle break down (GVBD), spindle formation, chromosome condensation and allows the transition from G2/M phase of meiosis [20]. Oocyte maturation is also under the control of auto/paracrine factors such as the transforming growth factor- $\beta$ (TGF $\beta$ ) superfamily. The TGF- $\beta$ superfamily is a large group of oocyte maturation regulatory molecules that include positive factors such as inhibins/activins [21] involving serine/threonine kinase receptors and the Smad proteins [22]. Tan and collaborators

*Corresponding author: Oliana Carnevali, Università Politecnica delle Marche, Dipartimento di Scienze del Mare, Via Brecce Bianche, 60131 Ancona, Italy, Tel.+39 071-2204990; Fax: +39 071-2204650; E-mail: o.carnevali@univpm.it

Received June 28, 2011; Accepted July 07, 2011; Published September 10, 2011

Citation: Gioacchini G, Lombardo F, Merrifield DL, Silvi S, Cresci A, et al. (2011) Effects of Probiotics on Zebrafish Reproduction. J Aquac Res Development S1:002. doi:10.4172/2155-9546.S1-002

Copyright: (c) 2011 Gioacchini G, et al. This is an open-access article distributed under the terms of the Creative Commons Attribution License, which permits unrestricted use, distribution, and reproduction in any medium, provided the original author and source are credited. 
[23] showed that smad2 is a key intracellular signalling molecule that mediates the positive effect of activin on oocyte maturation.

Therefore, the aim of the present study was to investigate the effects of the L. rhamnosus administration on ovarian development (both growth and maturation phases) and reproductive performance of zebrafish (D. rerio) females.

\section{Material and Methods}

\section{Animals and probiotic administration}

Adult female and male zebrafish (D. rerio) were purchased from a local supplier, Acquario di Bologna, Bologna (Italy) and kept in aquaria at $28^{\circ} \mathrm{C}$ with oxygenated water. Fish were fed twice daily with commercial feed (Vipagran, Sera, Germany) and another two times with Artemia salina. Eggs laid by parental fish were kept and grown. Six month old adult zebrafish were used for this study. Females were kept at $25.0 \pm 0.5^{\circ} \mathrm{C}, 14 \mathrm{~L}$ [400 lux]/10D [1 lux] (light on at 07:00) and divided into two groups ( $\mathrm{n}=13-15$ each). The control group (CTRL) was fed only on the commercial diet and the probiotic treated group (PROBIO) were fed on the commercial diet mixed with lyophilized probiotic. The experiment was repeated three times.

The probiotic strain used was Lactobacillus rhamnosus IMC $501^{\circledR}$ [24], provided by Synbiotec S.r.l. (Camerino, MC, Italy), and supplied in a commercial diet at a final concentration of $10^{6} \mathrm{CFU}$ (colony forming units) $\mathrm{g}^{-1}$.

Enumeration of spawned eggs was performed every day at 09:00 within $2 \mathrm{~h}$ after the lights came on. After ten days of treatment ten females from each experimental group were sacrificed by a lethal overdose of anesthesia (500 $\mathrm{mg} \mathrm{l}^{-1}$ MS-222 [3-aminobenzoic acid ethyl ester] buffered to $\mathrm{pH}$ 7.4; Sigma). All fish were measured for total wet weight $(\mathrm{mg})$ and ovary weight. To quantify gonadal growth in females, the ovaries were weighed (to the nearest $0.1 \mathrm{mg}$ ) and the gonadosomatic index (GSI) was calculated by expressing the gonad weight as a percentage of the total body weight.

The ovaries and liver were sampled and immediately flash-frozen using liquid nitrogen and stored at $-80^{\circ} \mathrm{C}$ until molecular biology analyses were performed; three-five ovaries from each group were removed for histological studies.

Procedures were performed in accordance with the Guidelines on the handling and Training of Laboratory Animals by the Universities Federation for Animal Welfare (UFAW) and with the Italian animal welfare legislation (D.L. 116/92).

\section{Detection of $L$. rhamnosus IMC $501{ }^{\circledR}$ in the intestinal tract by cultivation and by real-time PCR}

At the end of the trial, five individual fish per tank were sampled tically to isolate gastrointestinal (GI) material. A ten-fold serial dilution of the GI sample was prepared in a sterile saline solution after which triplicate aliquots of $50 \mu \mathrm{l}$ were spread-plated on de Man, Rogosa and Sharpe (MRS) media (OXOID, Basingstoke, Hampshire, UK) supplemented with vancomycin $\left(12 \mu \mathrm{gml}^{-1}\right)$. After $48-72 \mathrm{~h}$ of aerobic incubation at $37^{\circ} \mathrm{C}$ colonies were counted. Additionally, L. rhamnosus IMC $501^{\circledR}$ was quantified by Q-PCR [25] using the primers Y2, 5'-CCCACTGCTGCCTCCCGTAGGAGT-3' [25] and Lr, 5'-TGCATCTTGATTTAATTTTG-3' [26] under the following amplification conditions: $95^{\circ} \mathrm{C}$ for $10 \mathrm{~min}, 40 \mathrm{cycles} 94^{\circ} \mathrm{C} 30 \mathrm{sec}, 55^{\circ} \mathrm{C} 30 \mathrm{sec}$ and $72^{\circ} \mathrm{C} 2 \mathrm{~min}$. To determine the specificity of amplification, analysis of product melting curve was performed after the last cycle of each amplification. Realtime PCR was performed with the Mx3000 (Stratagene) and all PCRs were performed in triplicate. Quantitative data from MRS plating were subsequently used to generate a standard curve in which the bacterial cell numbers were plotted against the cycle threshold (CT) value, being the minimal cycle number at which the fluorescence signal exceeds the threshold level. The standard curve was generated from real-time PCR analysis of DNA extracts using 16S rRNA as the target gene. A linear relation between initial bacterial concentration and CT values was obtained in the range corresponding to $10^{5}-10^{9} \mathrm{CFU} \mathrm{ml}{ }^{-1}\left(\mathrm{R}^{2}=0.9914\right)$. L. rhamnosus was quantified by real-time PCR, interpolating the CT values with that of a standard curve [27].

\begin{tabular}{lll}
\hline \multicolumn{1}{c}{ Gene } & \multicolumn{1}{c}{ For Primer } & \multicolumn{1}{c}{ Rew Primer } \\
\hline Vtg1 & GCCAAAAAGTGGGTAAACA & AGTTCCGTCTGGATTGATGG \\
Era & GGTCCAGTGTGGTGCTCT & AGAAAGCTTTGCATCCCTCA \\
Cyp19a & CCGTTCTTATGGCAGGTGAT & TTGTGTGGTCGATGGTGTCT \\
Cyclin B & ATTCGGCCGAGGAGATAGT & GAGCCATCATTTCTCGTGGT \\
Activin $\boldsymbol{\beta} 1 \mathrm{a}$ & CAACTTAGATGGACACGCTG & GTGGATGTCGAGGTCTTGTC \\
Smad2 & CAACTTAGATGGACACGCTG & GTGGATGTCGAGGTCTTGTC \\
Smad2 & CTGACTGAGTTGCCACCTTTG & GGTCCATGCCATGATTGACAG \\
Cox2a & TGGATCTTTCCTGGGTGAAGG & GAAGCTCAGGGGTAGTGCAG \\
ARP & CTGAACATCTCGCCCTTCTC & TAGCCGATCTGCAGACACAC \\
\hline
\end{tabular}

Table 1: List of primer sequences used for Q-PCR analysis.

A

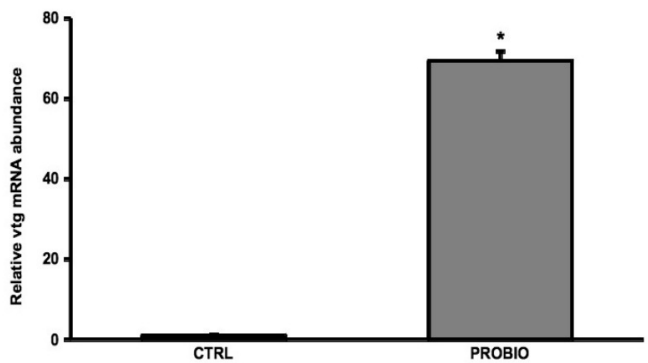

B

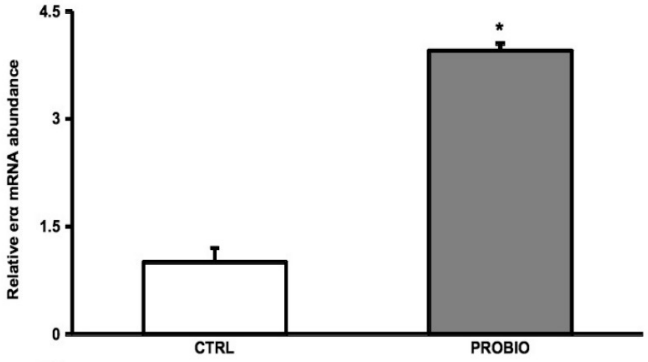

C

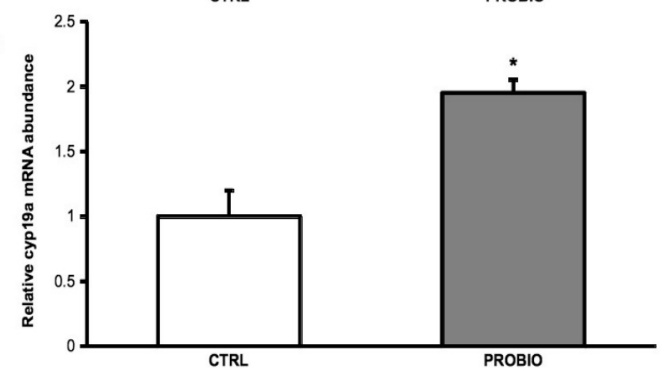

Figure 1: $(A)$ vtg (B) era mRNA levels in the liver and (C) cyp19a mRNA levels in the ovary, normalized against arp genes in zebrafish females fed on $L$ rhamnosus IMC $501^{\circledR}$ (PROBIO) and control diet (CTRL). Data are presented as mean values expressed as ratio to control $(n=10) \pm$ standard deviation (SD). Asterisks denote significant differences from the control group $(P<0.05)$ analyzed using Student's t-test. 
Citation: Gioacchini G, Lombardo F, Merrifield DL, Silvi S, Cresci A, et al. (2011) Effects of Probiotics on Zebrafish Reproduction. J Aquac Res Development S1:002. doi:10.4172/2155-9546.S1-002

Page 3 of 6

\section{Histological study}

Fixed gonads were prepared for histological examination using standard biological procedures. Gonads were embedded in paraffin wax and sectioned $(7 \mu \mathrm{m})$ with a microtome (HM355 microm). The sections were stained using picroindigocarmin (Fluka $\mathrm{n}^{\circ}$ 57000) and mounted in afcolene, then examined under a light microscope (Nikon 90i) with the software NIS-element AR.

\section{RNA extraction and CDNA synthesis}

Total RNA was extracted with TRI REAGENT ${ }^{\mathrm{TM}}$ (Sigma) following the manufacturer's protocol. Total RNA extracted was eluted in $25 \mu \mathrm{l}$ of RNAse-free water. Final RNA concentrations were determined by spectrophotometer and the RNA integrity was verified by ethidium bromide staining of $28 \mathrm{~S}$ and $18 \mathrm{~S}$ ribosomal RNA bands on $1 \%$ agarose gel. RNA was stored at $-80^{\circ} \mathrm{C}$ until use. Total RNA was treated with DNAse (10 UI at $37^{\circ} \mathrm{C}$ for $10 \mathrm{~min}$, MBI Fermentas) and a total amount of $1 \mu \mathrm{g}$ of RNA was used for cDNA synthesis, employing iScript cDNA Synthesis Kit (Bio-rad)

\section{Real time PCR}

PCRs were performed using the SYBR green method in a iQ5 iCycler thermal cycler (Bio-rad). Triplicate PCR reactions were carried out for each sample analyzed. The reactions were set on a 96-well plate by mixing, for each sample, $1 \mu \mathrm{l}$ of diluted $(1 / 20)$ cDNA, $5 \mu \mathrm{l}$ of $2 \mathrm{X}$ concentrated $\mathrm{iQ}^{\mathrm{TM}}$ SYBR Green Supermix (Bio-rad), containing SYBR Green as a fluorescent intercalating agent, $0.3 \mu \mathrm{M}$ forward primer and $0.3 \mu \mathrm{M}$ of reverse primer. The primer sequences are shown in Table
1. The thermal profile for all reactions was $3 \mathrm{~min}$ at $95^{\circ} \mathrm{C}$ and then 45 cycles of $20 \mathrm{sec}$ at $95^{\circ} \mathrm{C}, 20 \mathrm{sec}$ at $60^{\circ} \mathrm{C}$ and $20 \mathrm{sec}$ at $72^{\circ} \mathrm{C}$. Fluorescence monitoring occurred at the end of each cycle. Additional dissociation curve analysis was performed and showed in all cases one single peak.

The ARP was used as the house keeping gene in each sample in order to standardize the results by eliminating variation in mRNA and cDNA quantity and quality. No amplification product was observed in negative controls and no primer-dimer formations were observed. The data obtained were analyzed using the iQ5 optical system software version 2.0 (Bio-rad). Modification of gene expression is represented with respect to the control sample at the same time of the treatment.

\section{Statistical analysis}

Data presented are mean \pm SD for the number of experiments. Student's t-tests was used for comparison between the two experimental groups. $\mathrm{P}<0.05$ was considered significant.

\section{Results and Discussion}

\section{L. rhamnosus IMC $501{ }^{\circledR}$ presence in the zebrafish gut}

L. rhamnosus IMC $501{ }^{\circledR}$ had clear modulating effects on the gut microbiota of zebrafish adults fed the probiotic diet. Lactic acid bacterial ( $\mathrm{LAB}$, determined from MRS counts) levels, presumed to be L. rhamnosus, were $1.91 \times 10^{4} \pm 0.7 \times 10^{4} \mathrm{CFUg}^{-1}$ of zebrafish gut in the probiotic fed fish whereas $\mathrm{LAB}$ levels were too few to enumerate in the control group. Q-PCR methods confirmed these findings and revealed $1.89 \times 10^{5} \pm 0.7 \times 10^{5} \mathrm{CFUg}^{-1}$ of zebrafish gut of probiotic fed
A

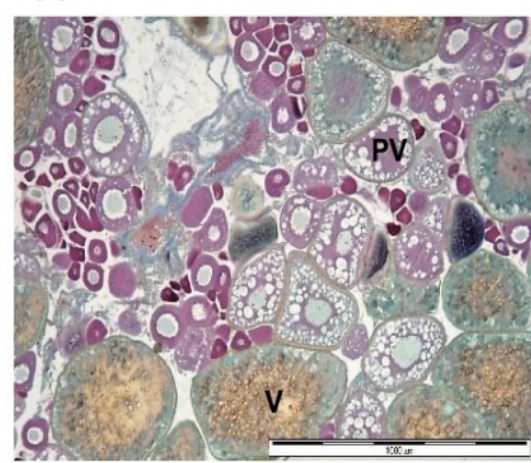

D

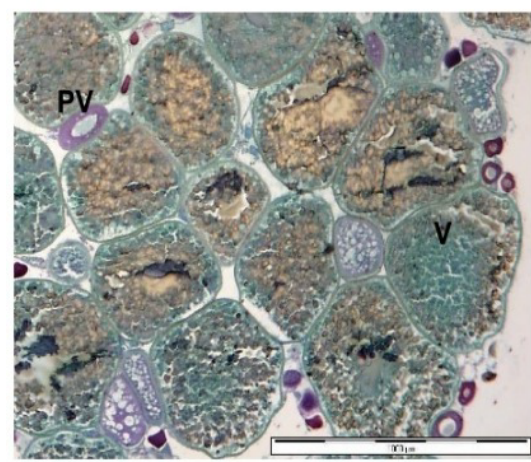

B

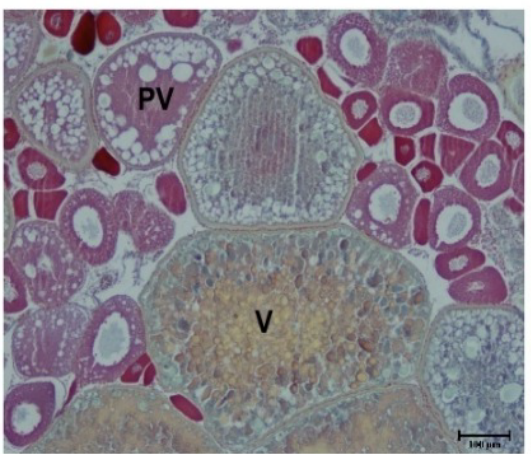

E



C



$\mathrm{F}$

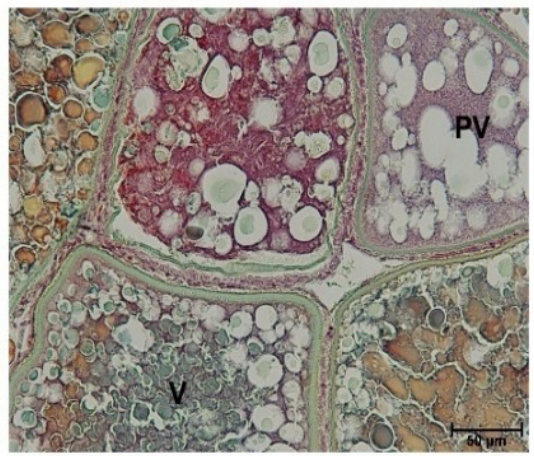

Figure 2: Representative micrographs of zebrafish ovaries from females fed the control $(A-C)$ and $L$. rhamnosus IMC $501^{\circledR}$ diet $(D-F)$. PV $=$ pre-vitellogenic follicles $\mathrm{V}=$ vitellogenic follicles. 
fish but none in the gut of the control group. These findings suggest that $L$. rhamnosus IMC $501^{\circledR}$ can populate the GI tract of zebrafish and likely influence host biological functions via interactions with the host at the mucosal interface. Similar findings have been observed in the false percula clownfish Amphiprion ocellaris [27]. Further studies are required to assess the level of host-microbe interaction using electron microscopy or histochemistry; additionally studies are required to determine whether such populations can truly colonise the GI tract or populations only persist with continual probiotic feeding as has been observed elsewhere $[28,29]$.

\section{Effects of L. rhamnosus IMC $501^{\circledR}$ on follicle growth}

In all oviparous vertebrates, ovary growth includes the vitellogenic process which consists of vtg gene transcription due to $\mathrm{E}_{2}$-ER complex binding on the Estradiol Responsive Element located on the vtg enhancing region [30]. Once synthesized, VTG is released into the blood stream and selectively incorporated by growing oocytes [31]. In zebrafish, probiotic administration induced a significant increase in both estradiol receptor (era) and vtg gene expression (Figure 1A-B). The increase in expression of these two genes in the liver was correlated with the significant increase in cyp19a expression at the ovarian level (Figure 1C). The cyp19a gene codifies for the enzyme responsible for converting androgen into estrogen. The higher level of this gene indicates a possible increase in plasma estradiol and, in turn, in VTG.

The involvement of probiotic on follicle growth phase was also supported by histological studies. The ovary sections evidenced an increase of vitellogenic follicles in fish fed the probiotic (Figure 2).

These changes were associated with a higher GSI found in fish administered with L. rhamnosus IMC $501^{\circledR}$ (Figure 3) and showed the involvement of L. rhamnosus IMC $501^{\circledR}$ in follicle growth.

\section{Effects of L. rhamnosus IMC $501^{\circledR}$ on oocyte maturation and ovulation}

In this study we found that probiotic administration significantly increased cyclin $\mathrm{B}$, activin $\beta \mathrm{A} 1$ and smad 2 gene expression which codify for important signals involved in the induction of oocyte maturation (Figure 4). The significant increase of cyclin B mRNA and therefore likely its protein, support the enhancement of the maturation phase by the probiotic administration. In zebrafish oocytes, cyclin B is undetectable prior to maturation [32]. Growing and full grown follicles express cyclin B mRNA but not thF protein. Microinjection of cyclin B protein or in vitro transcribed ccnb1 mRNA into zebrafish oocytes induces germinal

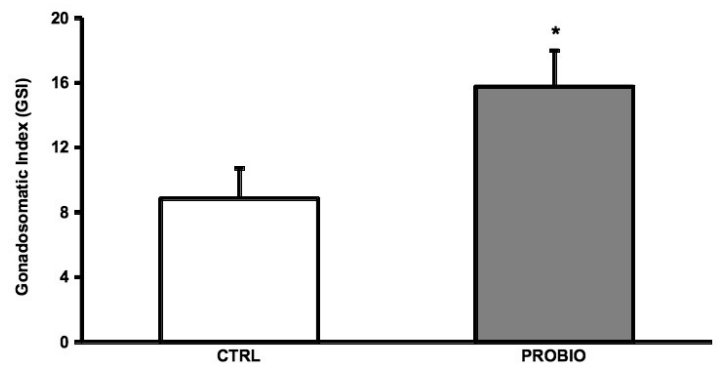

Figure 3: Gonadosomatic index (GSI) values of zebrafish females fed on $L$. rhamnosus IMC $501^{\circledR}(\mathrm{PROBIO})$ and control diet (CTRL). $(\mathrm{n}=10) \pm$ standard deviation (SD). Asterisks denote significant differences from the control group $(\mathrm{P}<0.05)$.
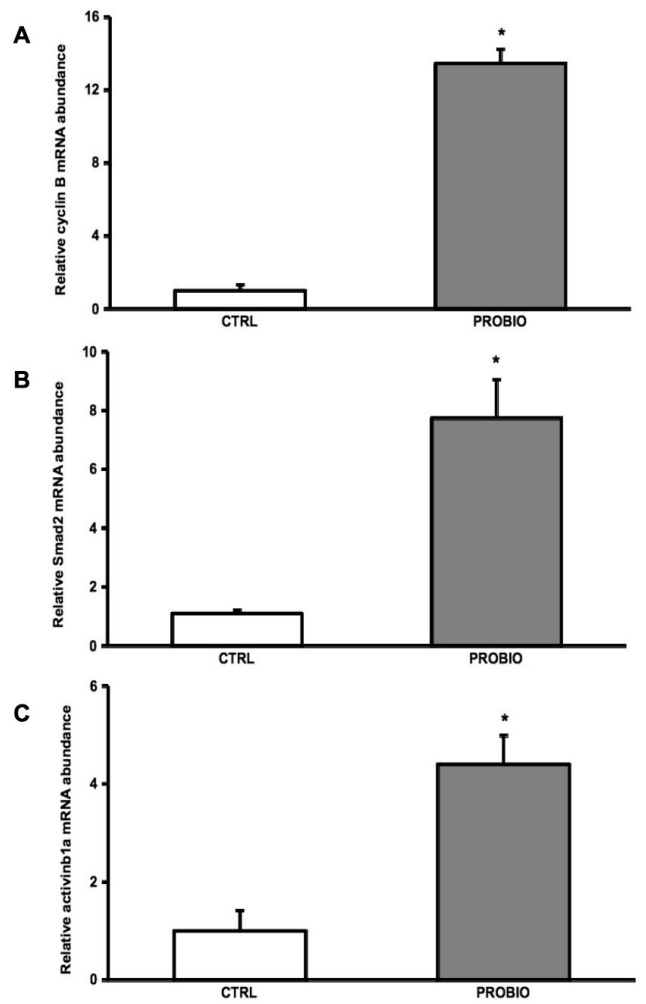

Figure 4: $(A)$ cyclin $B(B)$ smad2 and $(C)$ activin $\beta A 1$ mRNA levels in the ovary normalized against arp genes, in zebrafish females fed on $L$. rhamnosus IMC $501^{\circledR}$ (PROBIO) and control diet (CTRL). Data are presented as mean values expressed as ratio to control $(n=10) \pm$ standard deviation $(S D)$. Asterisks denote significant differences from the control group $(P<0.05)$.
A

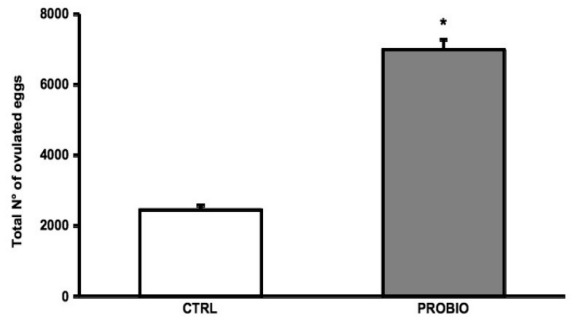

B

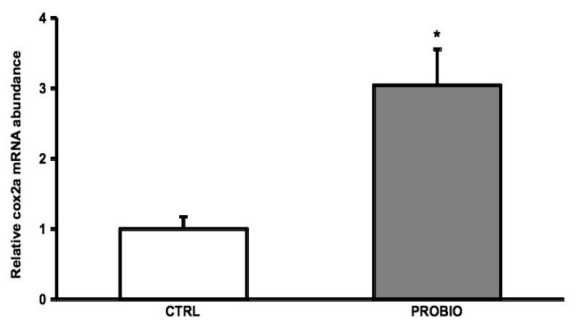

Figure 5: (A) Total number (ten days of treatment) of eggs spawned by zebrafish females fed on L. rhamnosus IMC $501^{\circledR}$ (PROBIO) and control diet (CTRL). (B) cox2a mRNA levels in the ovary, normalized against arp genes, in zebrafish females fed on L. rhamnosus IMC $501^{\circledR}$ (PROBIO) and control diet (CTRL). Data are presented as mean values expressed as ratio to control $(n=10) \pm$ standard deviation (SD). Asterisks denote significant differences from the control group $(\mathrm{P}<0.05)$ 
vesicle breakdown (GVBD), regardless of the oocyte developmental stage [33]. Many studies conducted with goldfish have confirmed that the translation of the "masked" cyclin B mRNA stored in immature oocytes is necessary, and sufficient, to induce oocyte maturation [32]. The results of the present study suggest that the induction of maturation phase due to probiotic administration is also mediated by the activation of activin. In fact, Tan and collaborators [23] observed that activin induces smad2 phosphorylation and microinjection of the smad2 antisense oligonucleotide into oocytes strongly decreased smad2 levels and completely reversed the effect of activin on oocyte maturation. In addition, knockdown of smad2 also significantly inhibited basal maturation rate, supporting the fundamental role of activin on oocyte maturation process [23].

Finally, the significant increase of the total numbers of ovulated eggs (Figure 5A) observed, concomitantly with the elevation of cox $2 \mathrm{a}$ (the enzyme in charge of prostaglandin biosynthesis which is the hormone responsible of ovulation) mRNA at the ovary level (Figure 5B), let us suppose that dietary L. rhamnosus IMC $501^{\circledR}$ administration can enhance ovulation through the activation of the cox 2 pathway and in turn exert a positive role on fecundity, providing additional information on the effects of probiotics on fish fecundity to previous evidences found in our laboratory $[8,9]$.

\section{Conclusion}

In this study, the effects of probiotic administration on ovarian development (both growth and maturation phases) and reproductive performance of zebrafish (D. rerio) females were evidenced.

Ten days probiotic administration resulted, at the physiological level, in a significant increase of gonadosomatic index (GSI) and of total numbers of eggs ovulated. These results were supported at the molecular level by the significant increase of expression of cyp19a, cyclin $\mathrm{B}$, activin $\beta \mathrm{A} 1$, smad 2 and cox- $2 \mathrm{a}$ genes in the ovary and vtg and era genes in the liver.

The significance of the results obtained herein underlines the importance of gut microbes in reproductive processes, supporting the hypothesis that feed additives could improve fecundity. Considering that the zebrafish has been clearly established as an excellent vertebrate model for reproduction and developmental research, these results support the potentiality of feed additives such as probiotics, frequently used in aquaculture practice, as a new technology to improve reproduction.

\section{Acknowledgements}

The authors wish to thank Madame Chantal Cuty, director of the plateau technique d'histologie of INRA-SCRIBE Rennes - France for the support for the histological study; Synbiotec S.r.I. for providing probiotic and Ocean soc coop for the technical support at the facilities. Grants: Fondi di Ateneo 2009 to Oliana Carnevali.

\section{References}

1. FAO/WHO (2001) Report on joint FAO/WHO expert consultation on evaluation of health and nutritional properties of probiotics in food including powder milk with live lactic acid bacteria. 1-4 October, Cordoba, Argentina.

2. Gatesoupe FJ (2008) Updating the importance of lactic acid bacteria in fish farming: natural occurrence and probiotic treatments. J Mol Microbiol Biotechnol 14: 107-114.

3. Merrifield DL, Dimitroglou A, Foey A, Davies SJ, Baker RTM, et al. (2010) The current status and future focus of probiotic and prebiotic applications for salmonids. Aquaculture 302: 1-18.

4. Carnevali O, Zamponi MC, Sulpizio R, Rollo A, Nardi M, et al. (2004) Administration of probiotic strain to improve sea bream wellness during development Aquacult Int 12: 377-386.
5. Carnevali O, De Vivo L, Sulpizio R, Gioacchini G, Olivotto I, et al. (2006) Growth improvement by probiotic in European sea bass juveniles (Dicentrarchus labrax, L.), with particular attention to IGF-1, Myostatin and Cortisol gene expression. Aquaculture 258: 430- 438.

6. Picchietti S, Mazzini M, Taddei AR, Renna R, Fausto AM, et al. (2007) Effect of administration of probiotic strains of GALT of larval gilthead seabream: immunohistochemical and ultrastructural studies. Fish Shellfish Immunol 22: 57-67.

7. Dimitroglou A, Merrifield DL, Carnevali O, Picchietti S, Avella AM, et al. (2011) Microbial manipulations to improve fish health and production--a Mediterranean perspective. Fish Shellfish Immunol 30: 1-16.

8. Gioacchini G, Maradonna F, Lombardo F, Bizzaro D, Olivotto I, et al. (2010) Increase of fecundity by probiotic administration in zebrafish (Danio rerio) Reproduction 140: 953-959.

9. Giorgini G, Conti C, Ferraris P, Sabbatini S, Tosi G, et al. (2010) Effects of Lactobacillus rhamnosus on zebrafish oocytes maturation: an FT-IR imaging and biochemical analysis. Anal Bioanal Chem 398: 3063-3072.

10. Fishman MC (2001) Genomics: Zebrafish--the canonical vertebrate. Science 294: 1290-1291.

11. Penberthy WT, Shafizadeh E, Lin S (2002) The zebrafish as a model for human disease. Front Biosci 7: 1439-1453.

12. Sumanas S, Lin S (2004) Zebrafish as a model system for drug target screening and validation. DDT: Targets 3: 89-96.

13. Lamason RL, Mohideen MA, Mest JR, Wong AC, Norton HL, et al. (2005) SLC24A5, a putative cation exchanger, affects pigmentation in zebrafish and humans. Science 310: 1782-1786.

14. Selman K, Wallace RA, Sarka A, Xiaoping Q (1993) Stages of oocyte development in the zebrafish, Brachydanio rerio. J Morphol 218: 203-224.

15. Wang Y, Ge W (2003a) Involvement of cyclic adenosine 3', 5'-monophosphate in the differential regulation of activin betaA and betaB expression by gonadotropin in the zebrafish ovarian follicle cells. Endocrinology 144: 491-499.

16. Wang Y, Ge W (2003b) Spatial expression patterns of activin and its signaling system in the zebrafish ovarian follicle: evidence for paracrine action of activin on the oocytes. Biol Reprod 69: 1998-2006.

17. Nagahama Y, Yoshikuni M, Yamashita M, Tokumoto T, Katsu Y (1995) Regulation of oocyte growth and maturation in fish. Curr Top Dev Biol 30: 103-145.

18. Calp MK, Matsumoto JA, Van Der Kraak G (2003) Activin and transforming growth factor- as local regulators of ovarian steroidogenesis in the goldfish. Gen Comp Endocr 132: 142-150.

19. Polzonetti-Magni AM, Mosconi G, Soverchia L, Kikuyama S, Carnevali O (2004) Multihormonal control of vitellogenesis in lower vertebrates. Int Rev Cytol 239: 1-46

20. Kajiura-Kobayashi H, Yoshida N, Sagata N, Yamashita M, Nagahama Y (2000) The Mos/MAPK pathway is involved in metaphase II arrest as a cytostatic factor but is neither necessary nor sufficient for initiating oocyte maturation in goldfish. Dev Genes Evol 210: 416-425.

21. Clelland E, Peng C ( 2009) Endocrine/paracrine control of zebrafish ovarian development. Mol Cell Endocrinol 312: 42-52.

22. Massagué J (2009) TGF-beta signal transduction. Annu Rev Biochem 67: 753-791.

23. Tan Q, Balofsky A, Weisz K, Peng C (2009) Role of activin, transforming growth factor-beta and bone morphogenetic protein 15 in regulating zebrafish oocyte maturation. Comp Biochem Physiol A 153: 18-23.

24. Verdenelli MC, Ghelfi F, Silvi S, Orpianesi C, Cecchini C, Cresci A (2009) Probiotic properties of Lactobacillus rhamnosus and Lactobacillus paracasei isolated from human faeces. Eur J Nutr 48: 355-363.

25. Young JP, Downer HL, Eardly BD (1991) Phylogeny of the phototrophic Rhizobium strain BTAi1 by polymerase chain reaction-based sequencing of a 16S rRNA gene segment. J Bacteriol 173:2 271-2277.

26. Ward LJH, Timmins MJ (1999) Differentiation of Lactobacillus casei, Lactobacillus paracasei and Lactobacillus rhamnosus by polymerase chain reaction. Lett Appl Microbiol 29: 90-92.

27. Avella AM, Olivotto I, Silvi S, Place AR, Carnevali O (2010) Effect of dietary probiotics on clownfish: a molecular approach to define how lactic acid bacteria modulate development in a marine fish. Am J Physiol Regul Integr Comp Physiol 298: 359-371. 
Citation: Gioacchini G, Lombardo F, Merrifield DL, Silvi S, Cresci A, et al. (2011) Effects of Probiotics on Zebrafish Reproduction. J Aquac Res Development S1:002. doi:10.4172/2155-9546.S1-002

28. Kim DH, Austin B (2006) Innate immune responses in rainbow trout (Oncorhynchus mykiss, Walbaum) induced by probiotics. Fish Shellfish Immunol 21 513-524.

29. Ferguson RMW, Merrifield DL, Harper GM, Rawling MD, Mustafa S, et al. (2010) The effect of Pediococcus acidilactici on the gut microbiota and immune status of on-growing red tilapia (Oreochromis niloticus). J Appl Microbiol 109: 851-862.

30. Teo BY, Tan NS, Lim EH, Lam TJ, Ding JL (1998) A novel piscine vitellogenin gene: structural and functional analyses of estrogen-inducible promoter. Mol Cell Endocrinol 146: 103-120.
31. Wallace RA, Selman K (1990) Ultrastructural aspects of oogenesis and oocyte growth in fish and amphibians. J Electron Microsc Tech 16: 175-201.

32. Nagahama Y, Yamashita M (2008) Regulation of oocyte maturation in fish. Dev Growth Differ 50: 195-219.

33. Kondo T, Yanagawa T, Yoshida N, Yamashita M (1997) Introduction of cyclinB induces activation of the maturation-promoting factor and breakdown of germinal vesicle in growing zebrafish oocytes unresponsive to the maturationinducing hormone. Dev Biol 190: 142-152. 